\title{
Pattern of spatial distribution of a brood-protecting schizasterid echinoid, Abatus cordatus, endemic to the Kerguelen Islands
}

\author{
Elie Poulin, Jean-Pierre Féral \\ Observatoire Océanologique de Banyuls, U.R.A. C.N.R.S. 117, F-66650 Banyuls-sur-Mer, France
}

\begin{abstract}
This study examined the spatial distribution at different geographic scales of the echinoid Abatus cordatus which is endemic to the Kerguelen Islands. Special attention was paid to the nondispersal strategy of the species. It lives burrowed in the sediment and females brood their young in dorsal pouches. The dispersal of this species is therefore characterised by a limited mobility among adults and the lack of a free-swimming larval phase. Using SCUBA and dredging. $A$. cordatus was sampled all around Kerguelen. The spatial distribution from the island scale to the bay scale show's discontinuities at 2 levels: (1) at the island level favourable sectors (principally characterised by jagged coastline with numerous sheltered bays) are separated by linear coastline or swell exposed sectors; (2) at the bay scale. A. cordatus lives in high density, isolated demes in shallow water of sheltered bays. A. cordatus was most numerous in sediments that ranged from medium to fine sand. The granulometry of the sediment and the lack of predation determine this aggregated spatial distribution pattern. Considering that the scale of larval dispersal is the consequence of spatial and temporal habitat structure, the non-dispersal strategy of $A$. cordatus is associated with a spatially varying but temporally constant habitat as predicted by theoretical models
\end{abstract}

KEY WORDS: Abatus - Brooding · Habitat limits - Kerguelen Non-dispersal strategy S Schizasteridae Spatial distribution $\cdot$ Subantarctic

\section{INTRODUCTION}

Species spatial distribution is the result of the interaction of biotic and abiotic constraints (Thrush 1991). In soft-bottom marine invertebrates and particularly deposit-feeders, functions such as feeding, respiration and motility are strongly linked to the sediment characteristics of the habitat. Generally, granulometry and the organic content of the sediment are the main factors that determine habitat (Lopez \& Levinton 1987). However the range of the habitat can be modified by biotic constraints, such as interspecific competition and predation; life-history factors may also influence spatial distribution (Thrush 1991). Larval dispersal and recruitment processes are also important factors related to spatial distribution. Indeed, factors such as length of larval stage duration, currents and site selection by larvae affect the spatial pattern of species (Thrush 1991)
Studies on the spatial distribution of organisms are important for several reasons (Thrush 1991). Firstly, the knowledge of distribution patterns is necessary to investigate population dynamics and genetics and, more generally, population biology. The different distribution patterns (aggregated, random or regular distribution) will determine the choice of a sampling design, in order to avoid bias in statistical analysis. Secondly, it is important to identify the factors responsible for the distribution patterns. Thirdly, there is the potential to understand the relationships between the spatial distribution and life-history traits, particularly for species without larval dispersal and that have low motility (Carlon \& Olson 1993).

The schizasterid echinoid Abatus cordatus (Verrill, $1876)$ is endemic to the Kerguelen Islands $\left(49^{\circ} 21^{\prime} \mathrm{S}\right.$, $70^{\circ} 12^{\prime} \mathrm{E}$ ) and is a deposit feeder that burrows a few centimetres below the surface of the sediment. The development of A. cordatus is direct (Schatt 1985, P. 
Schatt \& J.-P. Féral unpubl.) and the females brood their young. The juveniles are released on the sea floor near their mother. Some information on the distribution of A. cordatus is available (Magniez 1980, Schatt 1985. Mespoulhé 1992). This burrowing echinoid is often very abundant and high densities are found at shallow depth (0 to $2 \mathrm{~m}$ ) near beaches. Individuals in dense aggregations often touch or nearly touch each other. The goal of the present study was to establish the spatial distribution of $A$. cordatus at different spatial scales.

\section{METHODS}

Exploratory phase. Exploration using SCUBA diving and dredging (Charcot dredge) was made at different scales (Fig, 1): firstly at the island scale to evaluate the overall distribution of Abatus cordatus around Kerguelen; secondly at the scale of a large gulf with numerous scattered islands (Golfe du Morbihan); and thirdly at a bay scale. Densities of $A$. cordatus were estimated and density indices were attributed to each site: low $\left(<5\right.$ ind. $\mathrm{m}^{-2}$ ), medium ( 5 to 20 ind $\mathrm{m}^{-2}$ ) and high density ( $>20$ ind. $\mathrm{m}^{-2}$ ). The type of substratum was recorded.

Density transects: density and vertical and horizontal patterns of distribution. After the exploratory phase, 3 major study areas (Ile Haute, Anse du Halage and Port Couvreux, respectively Sites 5, 12 and 17 in Fig. 1), were selected for their high population densities. These are the locations of ecological and physiological studies (Magniez 1980, Schatt 1985, Mespoulhé 1992). At the 3 sites, we examined a transect of 50 or $100 \mathrm{~m}$ length from the beach towards the open

2* sea, until the echinoid density was zero.

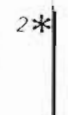

$2 *$
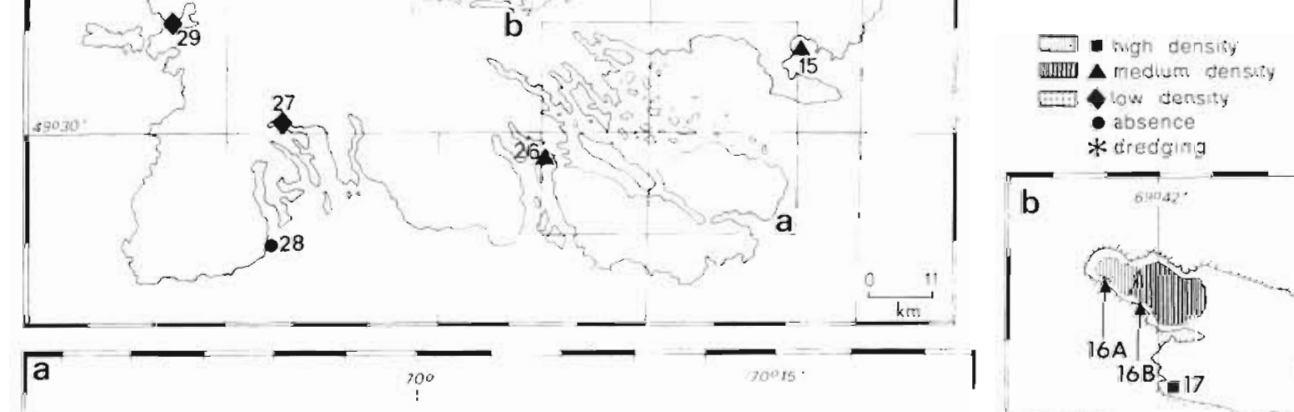

$\bar{b}$

* dredging

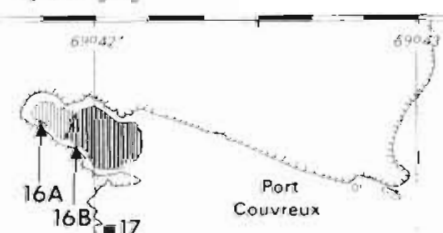

$16 B_{3}=17$ Couvreux

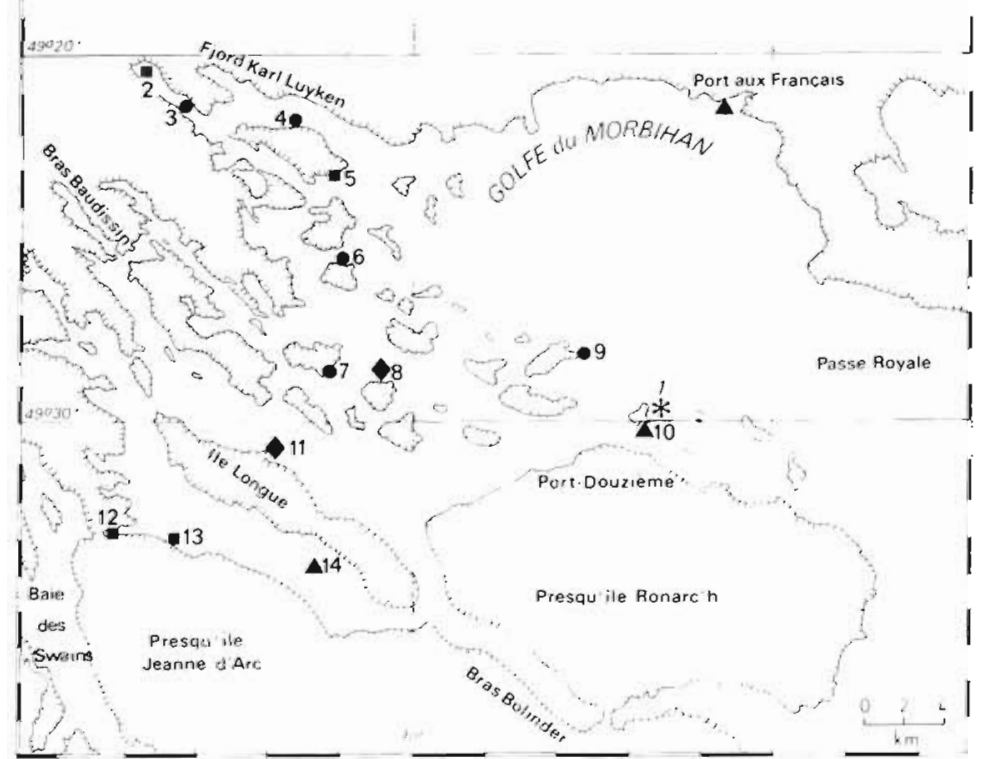

$\uparrow$

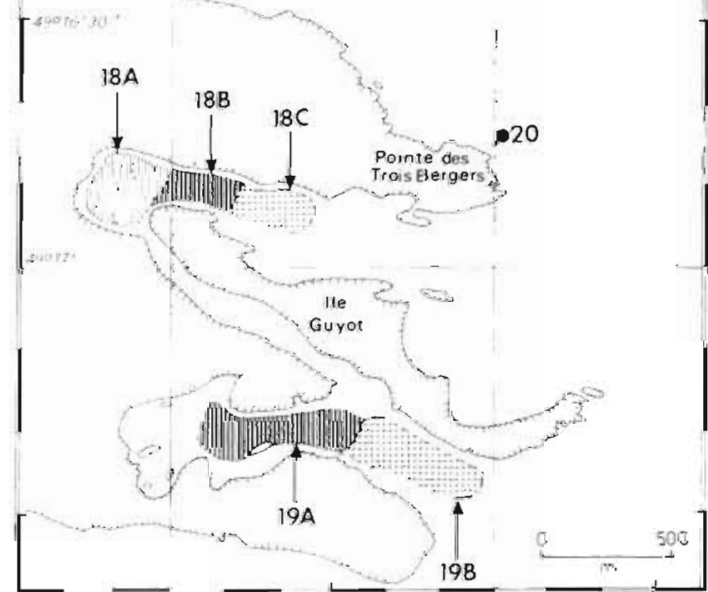

Fig. 1. Distribution pattern of Abatus cordatus around the Kerguelen Islands. (a) Golfe du Morbihan. (b) Bras de la Fonderie. Numbers correspond to the sites described in Table 1 
Quadrats $\left(0.5 \mathrm{~m}^{2}\right)$ were made every $10 \mathrm{~m}$, or more frequently if a topographical change occurred (e.g slope break, substrate texture, algal cover). All individuals found were removed from each quadrat and counted. This procedure of sampling by hand could underestimate the density of small individuals. Corresponding depths were regularly recorded with an electronic depth gauge in order to draw bottom profiles. Depths were calculated from the equinoctial low water Major features of the substratum and of algal composition and density were also noted.

At lle Haute a second perpendicular transect was carried out to circumscribe the population. Data from the 2 perpendicular transects were extrapolated to produce 3-dimensional plots of density and of bottom topography at this site. We used a gridding method, which uses geostatistical techniques to calculate the autocorrelation between data points and produce a minimal variance unbiased estimate ('kriging' option, SURFER Access System, Golden Software, Inc., Golden, CO, USA).

At Port Couvreux we repeated the same transect 1 yr later to establish the stability of the spatial distribution of high population densities.

Sediment sampling and analysis. Substrate samples (core-box, $5 \mathrm{~cm}^{2}$ ) from the upper 5 to $6 \mathrm{~cm}$ were taken at the location of the highest density of Abatus cordatus at Ile Haute, Anse du Halage and Port Couvreux to evaluate the particle size composition of the substratum. The localities of these sites are shown in Fig. 1. The particle-size frequency distribution were obtained by sieving the dried sediment through a series of sieves $(50,100,250,400,630,1000$ and $2000 \mu \mathrm{m})$.

\section{RESULTS}

\section{Distribution patterns}

Abatus cordatus is distributed all around the Kerguelen Islands (Fig. 1, Table 1). However, high density populations are found principally in sectors where the coastline is jagged and where bays are abundant (northwestern sector and Golfe du Morbihan). Only scattered and isolated individuals were found on the west coast (Site 29) which is swept by strong swell, and on the poorly jagged east coastline.

Investigations on the spatial distribution of Abatus cordatus at different scales indicate that discontinuities in the distribution occur at 2 levels: firstly, at the island level, where favourable sectors are separated by linear coastline or swell exposed sectors; secondly, at a smaller scale, where $A$. cordatus is distributed in small populations. Indeed, populations are generally characterised by high-density, isolated aggregations (up to 70 mature ind. per $0.5 \mathrm{~m}^{2}$ ) in favourable sites, in shallow water at the bottom of sheltered bays (Fig. 1b). However, isolated individuals were observed during SCUBA diving at up to $25 \mathrm{~m}$ depth on muddy sand, and have been reported down to $560 \mathrm{~m}$ depth (De Ridder et al. 1993) around Kerguelen.

\section{Transects}

Fig. 2 shows densities of mature Abatus cordatus along bottom profiles. At Ile Haute (Fig. 2a), the density increases rapidly in the subtidal zone to a maximum (34 ind. per $0.5 \mathrm{~m}^{2}$ ) at $0.2 \mathrm{~m}$ depth. Twenty metres from
Fig. 2. Density (top line) and topography (bottom line) profiles along transects. (a) Ile Haute; (b) Anse du Halage; (c) Port Couvreux (1991); (d) Port Couvreux (1992)
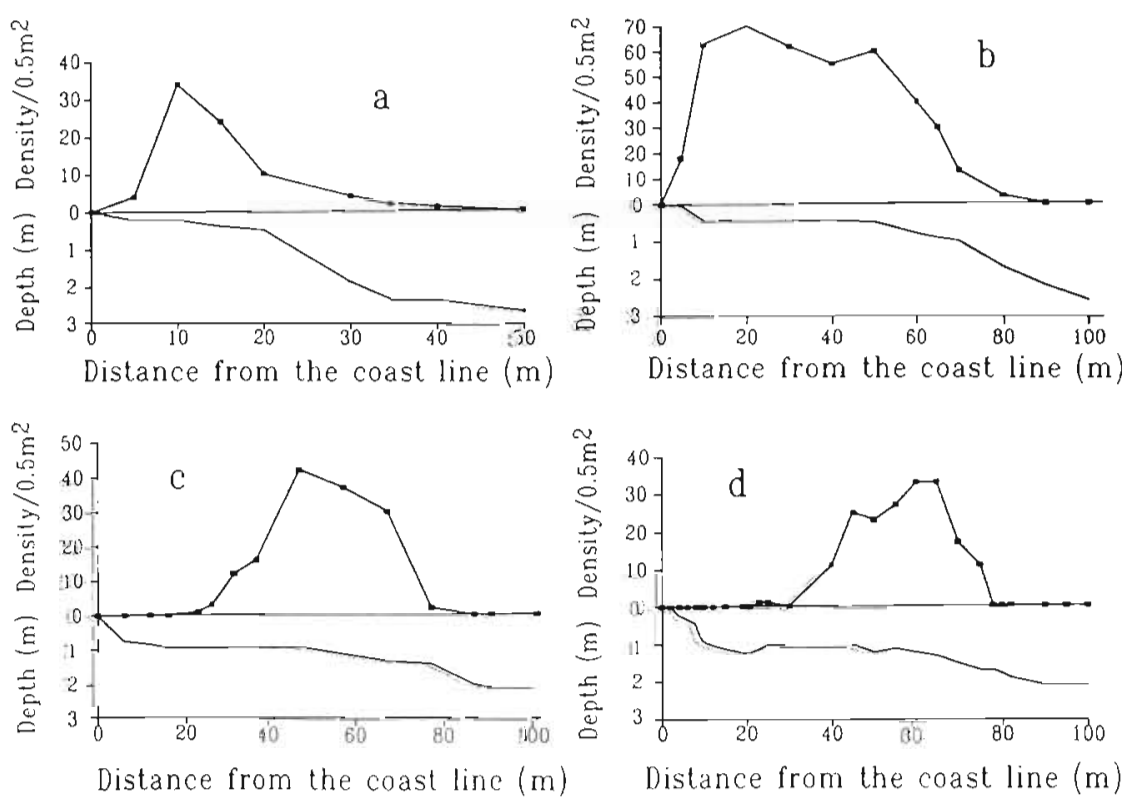
Table 1 Characteristics of sites where Abatus cordatus was found by SCUBA divers. Density index: low, $<5$ ind. $\mathrm{m}^{-2}$; medium, 51020 ind. $\mathrm{m}^{-2}$; high, $>20$ ind. $\mathrm{m}^{-2}$. Site numbers are shown in Fig. 1. "Sites trom this study

\begin{tabular}{|c|c|c|c|c|c|}
\hline No. & Site & Presence & Density index & Depth (m) & Biotope \\
\hline $1 \mathrm{~A}$ & Port Aux Français & No & - & $0-5$ & Kelp forest \\
\hline $1 \mathrm{~B}$ & Port Aux Français & No & - & 6 & Mud \\
\hline $1 \mathrm{C}$ & Port Aux Français & Yes & Medium & 8 & Muddy sand \\
\hline $1 \mathrm{D}$ & Port Aux Français & No & - & 25 & Mud \\
\hline $2 \mathrm{~A}$ & Port Raymond & Yes & High & $1-2$ & Sand \\
\hline $2 \mathrm{~B}$ & Port Raymond & Yes & Low & 5 & Mud \\
\hline 3 & Anse de Saint Malo & No & - & $0-26$ & Mud \\
\hline 4 & Bras Karl Luyken & No & - & $0-20$ & Mud \\
\hline $5 \mathrm{~A}$ & Ile Haute ${ }^{\circ}$ & Yes & High & $0-2$ & Sand \\
\hline $5 B$ & Ile Haute & No & - & 12 & Kelp forest \\
\hline $5 \mathrm{C}$ & Ile Haute & No & - & $0-12$ & Rocks \\
\hline $5 \mathrm{D}$ & Anse des Rennes & No & - & $0-14$ & Rocks \\
\hline 6 & Ile Heugh & No & - & $0-21$ & Mud \\
\hline 7 & Ile Mayes & No & - & $0-20$ & Mud \\
\hline 8 & Ile Blackney & Yes & Low & $0-10$ & Muddy sand \\
\hline 9 & Ile du Chat & $\mathrm{N}_{0}$ & - & $0-20$ & Rocks \\
\hline $10 \mathrm{~A}$ & Ile Shum & Yes & Medium & 15 & Muddy sand \\
\hline $10 \mathrm{~B}$ & Ile Shum & No & - & $0-24$ & Mud \\
\hline 11 & Port Bizet & Yes & Low & $0-20$ & Muddy sand \\
\hline 12 & Anse du Halage ${ }^{*}$ & Yes & High & $0-2$ & Sand \\
\hline $13 \mathrm{~A}$ & Port Jeanne D'Arc & Yes & High & $0-3$ & Sand \\
\hline $13 \mathrm{~B}$ & Port Jeanne D'Arr & No & - & $7-25$ & iviud \\
\hline $14 \mathrm{~A}$ & Ilots Glénan & Yes & Medium & 20 & Mud \\
\hline $14 \mathrm{~B}$ & Ilots Glénan & No & - & $20-30$ & Mud \\
\hline $15 \mathrm{~A}$ & Chateau d'If & No & - & 4 & Muddy sand \\
\hline $15 B$ & Baie Norvegienne & Yes & Medium & 3 & Sand \\
\hline $16 \mathrm{~A}$ & Anse Caron & Yes & High & $0-2$ & Sand \\
\hline $16 \mathrm{~B}$ & Anse Caron & Yes & Low & $10-15$ & Mud \\
\hline 17 & Port Couvreux & Yes & High & $0-2$ & Sand \\
\hline $18 \mathrm{~A}$ & Anse Aldebert & Yes & High & $0-2$ & Sand \\
\hline $18 \mathrm{~B}$ & Anse Aldebert & Yes & Medium & $3-8$ & Sand \\
\hline $18 \mathrm{C}$ & Anse Aldebert & No & - & 15 & Kelp forest \\
\hline $19 \mathrm{~A}$ & Anse Thomas & Yes & Medium & 6 & Sand \\
\hline $19 \mathrm{~B}$ & Anse Thomas & No & - & $7-12$ & Muddy sand \\
\hline 20 & Ilot des Trois Bergers & No & - & $0-30$ & Rocks \\
\hline 21 & Baie du Hopful & Yes & Low & $5-25$ & Muddy sand \\
\hline $22 \mathrm{~A}$ & Port Matha & Yes & High & $0-2$ & Sand \\
\hline $22 \mathrm{~B}$ & Port Matha & Yes & Medium & $4-8$ & Mud \\
\hline $22 \mathrm{C}$ & Port Matha & No & - & $10-22$ & Muddy sand \\
\hline $23 \mathrm{~A}$ & Baie du Brise-Lames & Yes & High & $0-2$ & Sand \\
\hline $23 \mathrm{~B}$ & Baie du Brise-Lames & Yes & High & $4-5$ & Sand \\
\hline $23 \mathrm{C}$ & Baie du Brise-Lames & No & $\sim$ & $3-13$ & Kelp forest \\
\hline $24 \mathrm{~A}$ & Anse du Jardin & Yes & High & $0-2$ & Sand \\
\hline $24 \mathrm{~B}$ & Anse du Jardin & Yes & Low & $10-27$ & Muddy sand \\
\hline 25 & Port Chrismas & No & - & $13-20$ & Muddy sand \\
\hline 26 & Baie des Swains & Yes & Medium & $0-3$ & Sand \\
\hline $27 \mathrm{~A}$ & Fjord des Portes Noires & No & - & $0-6$ & Mud \\
\hline $27 \mathrm{~B}$ & Fjord des Portes Noires & Yes & Low & $0-25$ & Mud \\
\hline 28 & Anse de Larmor & No & - & $0-1$ & Sand \\
\hline $29 \mathrm{~A}$ & Baie du Noroit & No & - & $0-5$ & Sand \\
\hline $29 \mathrm{~B}$ & Baie du Noroît & No & - & $0-3$ & Sand \\
\hline $29 \mathrm{C}$ & Pointe Berger & Yes & Low & $0-8$ & Sand \\
\hline 30 & Baie de la Mouche & Yes & High & $0-2$ & Sand \\
\hline
\end{tabular}

the coast, the bottom drops rapidly from 0.5 to $2.5 \mathrm{~m}$ and A. cordatus become progressively more isolated.

At Anse du Halage (Fig. 2b), the distribution profile is similar to the preceding one, although the high den- sity area is much wider and the density itself is twice as great ( 70 ind. per $0.5 \mathrm{~m}^{2}$ ). Again, the decrease of $A b a$ tus cordatus density is correlated with a change in the bottom profile 

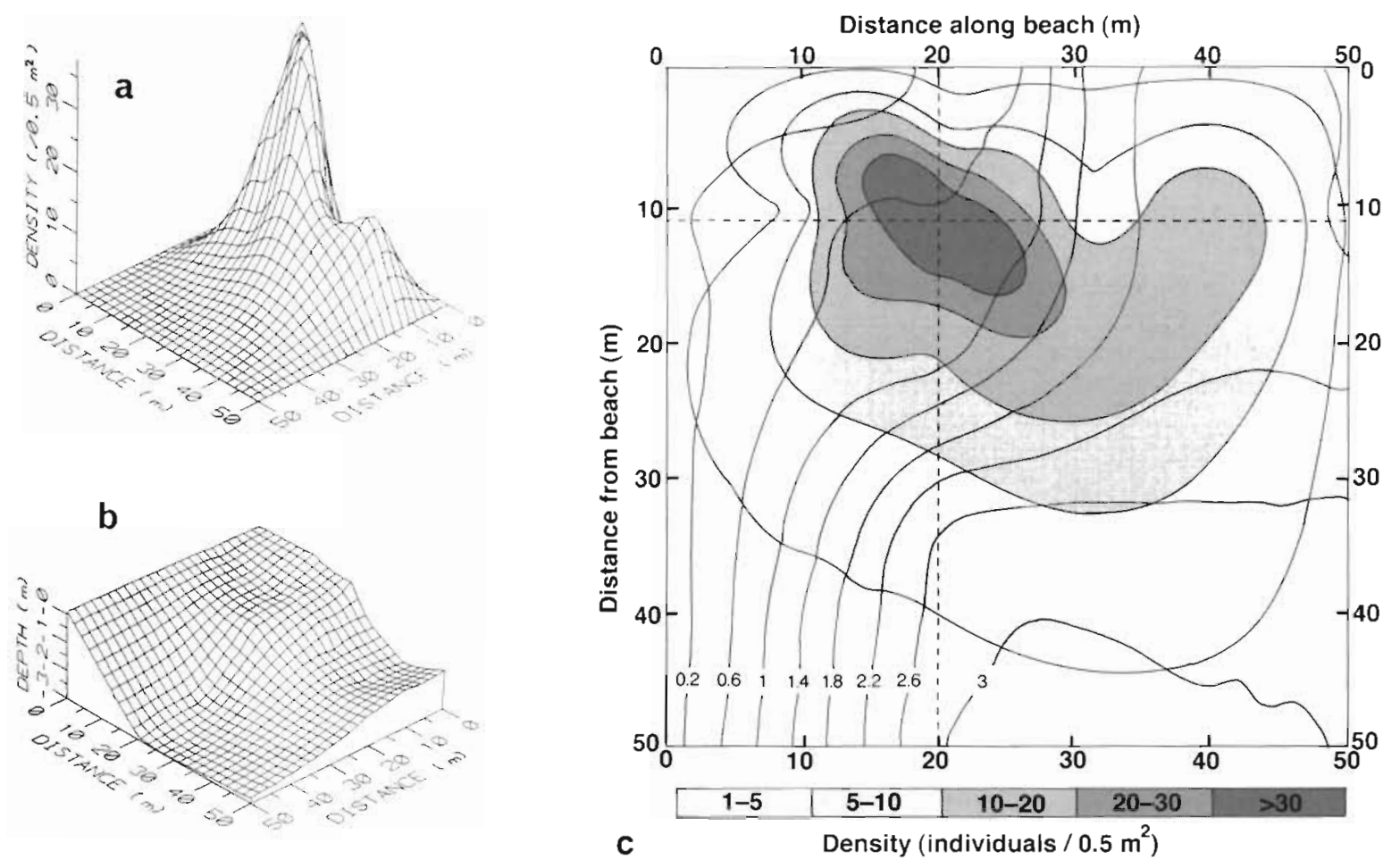

Fig. 3. Three-dimensional plot of (a) Abatus cordatus density and (b) topography of the site based on 2 perpendicular transects at the Ile Haute (SURFER 'kriging' option). (c) Two-dimensional representation of A. cordatus density distribution at Ile Haute. Levels of grey show density (ind. per $\left.0.5 \mathrm{~m}^{2}\right) ;(-)$ isobaths $(\mathrm{m}) ;(---)$ transect lines

At Port Couvreux (Fig. 2c), the peak of density is deeper $(1.5 \mathrm{~m})$ and the first individuals encountered are $20 \mathrm{~m}$ from the coastline. However, the lower limit is unchanged and the density also decreases greatly when the depth reaches $2 \mathrm{~m}$. One year later (Fig. 2d), the distribution profile was relatively unchanged but the bottom profile shows some differences along the first $30 \mathrm{~m}$ of the transect, indicating a marked influence of the hydrodynamic activity of the area. This was confirmed by the observation of deep ripple marks in 1991 and 1992 .

In all areas, Abatus cordatus showed a peak of density in the shallow subtidal zone. At Ile Haute and Anse du Halage, these peaks began not far below the lower tide level while it was typically deeper at Port Couvreux. Field observations showed that $A$. cordatus was not found in high energy sites (west and northeastern coasts).

The occurrence of Abatus cordatus is shown in terms of 3-dimensional plots of density (Fig. 3a), bottom topography (Fig. 3b) at Ile Haute, and 2-dimensional projections (Fig. 3c). Most of the population is localised on a small plateau between 0.2 and $1 \mathrm{~m}$ depth and the entire population lives on a $2500 \mathrm{~m}^{2}$ surface. The estimated density was 10 to $15 \times 10^{3}$ mature individuals at this site (test length $>27 \mathrm{~mm}$ for females and $19 \mathrm{~mm}$ for males; Magniez 1980).

\section{Particle size distribution}

The particle size distributions of the substrata of the 3 high density areas are shown in Fig. 4. At lle Haute and Anse du Halage the sediment in which Abatus cordatus was found falls within the limits of sand $(2.0$ to $0.063 \mathrm{~mm}$ grain size) with medium to fine/medium

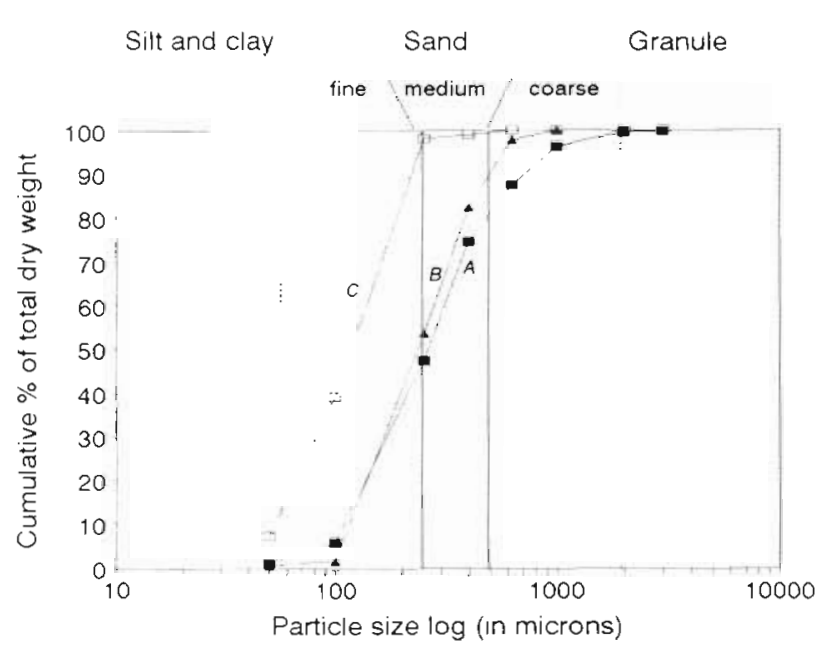

Fig. 4. Size frequency distribution (in cumulative percent) of the substrata of: A, lle Haute (- $)$; B, Anse du Halage (A); C. Port Couvreux (口) 
sand grades predominant. At Port Couvreux samples were characterised by a finer sand, with a low percentage of silt and clay $(<20 \%)$.

\section{DISCUSSION}

\section{Distribution pattern and habitat limits}

The spatial distribution of Abatus cordatus is characterised by numerous, dense, isolated populations in shallow water $(0$ to $3 \mathrm{~m}$ ) and scattered individuals to $560 \mathrm{~m}$ depth. This dispersed distribution in high density demes appears to be the consequence of a specific habitat. The upper limit is the lowest tide level in sheltered sites, or the depth limit of swell action in less sheltered sites, as in Port Couvreux. Indeed lle Haute and Anse du Halage are very sheltered but Port Couvreux is more exposed to the swell. These data indicate that $A$. cordatus is intolerant of wave action and the displacement of the peak of density to a deeper zone at Port Couvreux may be related to this factor. Generally density decreases ıdpidiy at less inan $2 \mathrm{~m}$ depth. The particle size composition of the substratum is usually a primary factor determining the habitat of depositfeeders. It influences both respiratory and locomotory functions (Lopez \& Levinton 1987).

Since Abatus cordatus lacks a sophisticated respiratory-current-producing mechanism such as a respiratory funnel or sanitary drain, it could be limited to coarse sediments in shallow waters because of the need to maintain sufficient water flow (Higgins 1974). The relatively Iarge pore space in coarse, well-sorted sediment probably allows a better flow of oxygenated water. As in many other spatangoids (see Chesher 1969 for a review; Ferber \& Lawrence 1976, Schinner 1993), A. cordatus emerges from the sand under conditions of oxygen deprivation in aquaria, when water circulation stops. In general, irregular echinoids, which inhabit fine sediments, excavate specialised respiratory connections with the surface (De Ridder 1982, Kanazawa 1991). The oxygen consumption rate of $A$. cordatus (Guille \& Lasserre 1979, Magniez \& Féral 1988 ) is comparable to that of the urchin Cassidulus caribbearum (Gladfelter 1978). This is relatively high compared to other burrowing echinoids (Webster 1975 , Gladfelter 1978, Magniez \& Féral 1988). It also supports the idea that, like Cassidulus spp., A. cordatus is limited to well-aerated substrata (Gladfelter 1978, Freire et al. 1992).

A number of irregular echinoid species show a decrease of burrowing and locomotory abilities in finer sediments (Lawrence \& Ferber 1971, Ferber \& Lawrence 1976, Lawrence \& Murdoch 1977). Abatus cordatus could also have such problems when the sed- iment becomes finer with increasing depth. Therefore, the substratum particle size may be a limiting factor controlling the localisation of high density populations.

In addition to abiotic constraints which determine the range of the habitat, biotic factors such as interspecific competition (Thompson 1982) and predation can affect distribution patterns. Generally, when prey display an aggregated spatial pattern, predators concentrate their feeding in the richest patches and tend to equalise prey density (Schneider 1978, Sih 1982, Botton 1984). Predation on Abatus cordatus was never observed in the field but organic parts of broken specimens are rapidly eaten by Serolis spp. (Isopoda: Crustacea) that are very abundant in the subtidal area. It seems unlikely that they attack healthy individuals but perhaps they prey on very young ones. Gulls Larus dominicanus are potential predators because of the low depth at low tide at which the highest densities of A. cordatus are found, but predation has not been observed. The burrowing habits of $A$. cordatus make them invisible for predatory birds. Gastropods are frequently described as important predators for irregular echinoids (Chesher 1969, Dix 1970, Hughes \& Hughes 1971 1981, Gladfelter 1978, McClintock \& Marion 1993) but the lack of holes in beached tests indicates that they are not predators of $A$. cordatus. It is therefore probable that predation does not contribute to the spatial distribution of $A$. cordatus. Likewise interspecific competition certainly does not play a role on spatial pattern because of the quasi-monospecific pattern of populations.

The presence of high density populations of Abatus cordatus is probably determined by the nature of the substrata and lack of turbulence. The occurrence of scattered individuals in the adjacent deeper zones and generally with different types of substrata (often muddy sediments) indicate that $A$. cordatus can live in very different habitats, but these individuals are often found on the surface of the sediment (Fig. 5). Moreover, the absence of small individuals in these areas suggests recruitment is very low or absent in such places and that high density zones function as nurseries. The movement towards deeper zones could arise when the individuals are large enough to manipulate different substrata, as suggested by Lawrence \& Ferber (1971) for Lovenia elongata, or young could remain stationary during the early period of growth as proposed by Chesher (1969) for Meoma ventricosa.

\section{Distribution pattern and non-dispersal strategy}

Some authors (Jackson 1968, Carlon \& Olson 1993) have considered larval dispersal distance as an explanation for adult spatial patterns. From this point of 


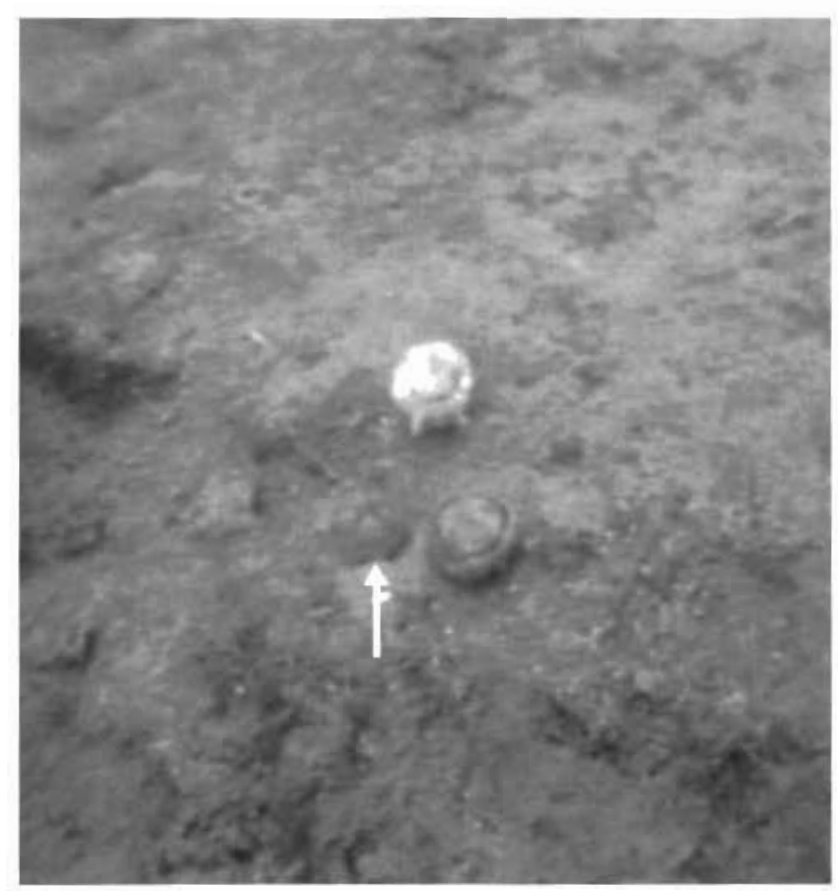

Fig. 5. Videotape frame showing 2 specimens of Abatus cordatus ( $45 \mathrm{~mm}$ length) on the surface of a muddy sediment at Kerguelen (Pointe du Zodiac, extremity of the north coast of the Anse du Halage, $7 \mathrm{~m}$ depth) and 1 just below the surface of the sediment (arrow)

view, an aggregated distribution may result from short larval dispersal time, simultaneous or gregarious settlement, or habitat selection by larvae. In the case of Abatus cordatus, if the brood-protecting strategy and the release of young on the bottom near their mother could produce high-density, isolated populations, the mobility of the burrowing echinoid would prevent population discontinuities. This hypothesis is therefore conceivable only for sessile organisms.

Another approach considers the scale of larval dispersal as the consequence of spatial and temporal habitat structure. Indeed, from a number of models, the heterogeneity and/or the instability of habitat have been recognised as fundamental features which accord with optimal dispersal strategies (Gadgil 1971, Roff 1974, Frank 1981, Hastings 1983, Hardin et al. 1990, McPeek \& Holt 1992). Temporal variation of carrying capacities (which reaches zero in the case of extinction) will favour dispersion because of the necessity to recolonize free habitats. On the other hand, when spatial variability of carrying capacities increases, the probability for a propagule to reach a 'good' site decreases. Thus, the balance of temporal and spatial variations of carrying capacities of habitat determines an optimal dispersal strategy for the species. Table 2 shows the optimal dispersal strategies under varying
Table 2. Optimal dispersal strategies under varying habitat heterogeneity and instability

\begin{tabular}{|lcc|}
\hline & No perturbation & Perturbatons \\
\hline $\begin{array}{l}\text { No spatial } \\
\text { heterogeneity }\end{array}$ & No & Dispersal \\
$\begin{array}{l}\text { Spatial } \\
\text { heterogeneity }\end{array}$ & No & Mispersal \\
\hline
\end{tabular}

habitat heterogeneity and instability. The non-dispersal strategy is favoured only if the habitat is heterogeneous (in terms of low and high density sites) and if habitat is stable in time (in the sense of persistence).

In Abatus cordatus, if spatial heterogeneity seems clearly established because of the discontinuity of the habitat (dense, isolated demes), it is more difficult to prove the time-stability of those populations. However, we have some indications: (1) The high density populations are always found in sheltered bays where tidal currents and wave action are weak. Indeed this region is known for frequent storms, and the swells can be devastating for shallow sea-floor and beaches. (2) An indication of the time stability is given by a 10 y study at the reference site Anse du Halage. We observed during this time neither a crash, nor an important variation in the density of $A$. cordatus. Moreover, a replicate of the transect in Port Couvreux 1 y later showed no difference in the general distribution pattern of this species in spite of a modification of the topographic profile probably due to a limited swell. (3) Another indication is given by the age structure of the population observed at the Anse du Halage in December 1992. An exhaustive sampling of quadrats $\left(2 \mathrm{~m}^{2}\right)$ allows us to reconstruct an age pyramid that indicates a regular recruitment for at least 5 yr (Féral \& Poulin 1994). As a result, A. cordatus fits the prediction of such models, and its non-dispersal strategy, in this case, is associated with a spatially varying but temporally constant habitat. Our case study thus contributes to an evaluation of models of dispersion, but does not substantially support them. Other examples are needed to validate the importance of temporal and spatial habitat structure on evolution of the dispersal strategies.

Acknowledgements. This work was supported by specific grants from the Institut Français pour la Recherche et la Technologie Polaires (formerly T.A.A.F. Mission de Recherche) 'BENTHOS/MAC' program. We thank the I.F.R.T.P. for facilities in Kerguelen. We are grateful to M. $J$. Bodiou for drawing the maps. Thanks are also due to P. Schatt for discussions and help in the field and to $V$. Andersen for allowing us to use her SURFER software. We are grateful to J. M. Lawrence for reading the manuscript. Wi: also thank him and 2 anonymous referees for helping us to improve the English text. 


\section{LITERATURE CITED}

Botton, M. L. (1984). Spatial distribution of three species of bivalves on a intertidal. flat: the interaction of life-history strategy with predation and disturbance. Veliger 26: 282-287

Carlon, D. B., Olson, R. R. (1993). Larval dispersal distance as an explanation for adult spatial pattern in two Caribbean reef corals. J. exp. mar. Biol. Ecol. 73: 247-263

Chesher, R. H. (1969). Contributions to the biology of Meoma ventricosa (Echinoidea: Spatangoida). Bull. mar. Sci. 19: $72-110$

De Ridder, C. (1982). Food and feeding mechanisms: Echinoidea. In: Jangoux, M., Lawrence, J. (eds.) Echinoderm nutrition. Balkema, Rotterdam, p. 105-115

De Ridder, C., David, B., Larrain, A. (1993). Antarctic and subantarctic echinoids from 'Marion Dufresne' expeditions MD03, MD04, MD08 and from the 'Polarstern' expedition Epos III. Bull. Mus, natn. Hist. nat., Paris (Sér. 4, Sect. A) 14: $405-441$

Dix, T. G. (1970). Biology of Evechinus chloroticus (Echinoidea: Echinometridae) from different localities. N.Z. J. mar. Freshwat. Res. 3: 13-16

Feral, J.-P. Poulin, É. (1994). Growth, recruitment and age structure of Abatus cordatus, a brood protecting schizasterid. SCAR sixth biology symposium. Antarctic communities: species, structure and survival, Venice, 30 May3 June 1994. Univ, Padova, Padova, p. 91

Ferber, $i$., Lawrence, J. M. (1976). Distribution, substratum preference and burrowing behaviour of Lovenia elongata (Gray) (Echinoidea: Spatangoida) in the Gulf of Elat ('Aqaba), Red Sea. J. exp. mar. Biol. Ecol. 22: 207-225

Frank, P. W. (1981). A condition for a sessile strategy. Am. Nat. 118: 288-290

Freire, C. A., Santos, P. J. P., Fontoura, N. F., Magalhăes, R. A. O., Grohmann, P. A. (1992). Growth and spatial distribution of Cassidulus mitis (Echinodermata: Echinoidea) on a sandy beach in Southeastern Brazil. Mar. Biol. 112: $625-630$

Gadgil, M. (1971). Dispersal: population consequences and evolution. Ecology 52: 253-261

Gladfelter, W. B. (1978). General ecology of the cassiduloid urchin Cassidulus caribbearum. Mar. Biol. 47: 149-160

Guille, A., Lasserre, P. (1979). Consommation d'oxygène de l'oursin Abatus cordatus (Verrill) et activité oxydative de son biotope aux îles Kerguelen. Mém. Mus. natn. Hist. nat., Paris, N.S. 43: 211-219

Hardin, D. P., Takac, P., Webb, G. F. (1990). Dispersion population models discrete in time and continuous in space J. Math. Biol. 28: 1-20

Hastings, A. (1983). Can spatial variation alone lead to selection for dispersal? Theor. pop. Biol. 24: 244-251

Higgins, R. C. (1974). Observations on the biology of Apatopygus recens (Echinoidea: Cassiduloida) around New Zealand. J. Zool., Lond. 173: 505-516

Hughes, R. N., Hughes, H. P. I. (1971). A study of the gastropod Cassis tuberosa (L.) preying upon sea urchins. J. exp mar. Biol. Ecol. 7: 305-314

Hughes, R. N., Hughes, H. P. I. (1.981). Morphological and behavioural aspects of feeding in Cassidae (Tonnacea,
Mesogastropoda). Malacologia 20: 385-402

Jackson, J. B. C. (1968). Bivalves: spatial and size-trequency distributions of two intertidal species. Science 161 $479-480$

Kanazawa, K. (1991). Burrowing mechanism and test profile in spatangoid echinoids. In: Yanagisawa, T. Yasumasu, I., Oguro, C. Suzuki, N., Motokawa, T (eds.) Biology of Echinodermata. Balkema, Rotterdam, p. 147-151

Lawrence, J. M., Ferber, I. (1971). Substrate particle size and the occurrence of Lovenia elongata (Echinodermata: Echinoidea) at Taba, Gulf of Elat (Red Sea). Israel J. Zool. 20: $131-138$

Lawrence, J. M., Murdoch, J. (1977). The effect of particle size frequency distribution of the substratum on the burrowing ability of Chiridota rigida (Semper) (Echinodermata: Holothuroidea). Mar. Behav. Physiol. 4: 305-311

Lopez, G. R., Levinton, J. S. (1987). Ecology of deposit-feeding animals in marine sediments. Q. Rev. Biol. 62: 235-259

Magniez, P. (1980). Le cycle sexuel d'Abatus cordatus (Echinoidea: Spatangoida): modalité d'incubation et évolution histologique et biochimique des gonades. Thèse Univ. P. et $M$. Curie, Paris 6

Magniez, P, Féral, J.-P. (1988). The effect of somatic and gonadal size on the rate of oxygen consumption in the subantarctic echinoid Abatus cordatus (Echinodermata) from Kerguelen. Comp. Biochem. Physiol. 90A: 429-434

McClintock, J. B., Marion, K. R. (1993). Predation by the king helmet (Cassis tuberosa) on six-holed sand dollars (Leodia sexiesperforata) at San Salvador, Bahamas. Bull. mar. Sci. 52: 1013-1017

McPeek, M. A., Holt, R. D. (1992). The evolution of dispersal in spatially and temporally varying environments. Am. Nat. 140: 1010-1027

Mespoulhé, P. (1992). Morphologie d'un échinide irrégulier subantarctique de l'archipel des Kerguelen: ontogenèse, dimorphisme sexuel et variabilité. Thèse, Univ. de Bourgogne, Dijon

Roff, D. A. (1974). Spatial heterogeneity and the persistence of populations. Oecologia 15: 245-258

Schatt, P. (1985). Développement et croissance embryonnaire de l'oursin incubant $A$ batus cordatus (Echinoidea: Spatangoida). Thèse, Univ. P. et $M$. Curie, Paris 6

Schinner, G. O. (1993). Burrowing behavior, substratum preference, and distribution of Schizaster canaliferus (Echinoidea: Spatangoida) in the northern Adriatic Sea. P.S.Z.N. I: Mar. Ecol. 14: 129-145

Schneider, D. C. (1978). Equalization of prey number by migratory shorebirds. Nature 271: 353-354

Sih, A. (1982). Optimal patch use: variation in selective pressure for efficient foraging. Am. Nat. 120: 666-685

Thompson, J. K. (1982). Population structure of Gemma gemma (Bivalvia: Veneridae) in south San Francisco Bay, with a comparison to some northeastern United States estuarine populations. Veliger 24: 281-290

Thrush, S. F. (1991). Spatial patterns in soft-bottom communities. TREE 6: 75-79

Webster, S. K. (1975). Oxygen consumption in echinoderms from several geographical locations, with particular reference to the Echinoidea. Biol. Bull. 148: 1.57-164

Manuscript first received: June 23, 1994

Revised version accepted: December 5, 1994 